\title{
Effect of a training program for promoting the mental health of nursing students in Zagazig University
}

\author{
Hanem A.A. Ahmed ${ }^{1}$, Safaa M. Metwally ${ }^{1}$, Mona M. Abd El-Maksoud *2,3 \\ ${ }^{1}$ Psychiatric and Mental Health Nursing, Faculty of nursing, Zagazig University, Egypt \\ ${ }^{2}$ Community Health Nursing, Faculty of nursing, Helwan University, Egypt \\ ${ }^{3}$ Nursing College, King Khalid University, Saudi Arabia
}

Received: August 23, 2016

DOI: $10.5430 /$ jnep.v7n6p10
Accepted: November 2, $2016 \quad$ Online Published: January 11, 2017

URL: http://dx.doi.org/10.5430/jnep.v7n6p10

\begin{abstract}
Mental health is a vital and necessary component of health. Mental health promotion creates positive environments for the good mental health and wellbeing of populations. This study aimed to evaluate the effectiveness of the training program on promoting mental health of nursing students. Aquasi-experimental design was used. A convenience sample included 130 nursing students from the nursing program at Zagazig University were randomly assigned to intervention and control groups. Participants completed the Thai Defense Style Questionnaire 40 (DSQ-40) and Sense of Coherence Questionnaire (SOC-29). Prior to the implementation of training program, mean scores on both measures did not differ significantly between the intervention and control group. However there were significant differences between both groups before and after the intervention. The current findings supported the efficiency of mental health promotion program. Therefore, it is essential to conduct further structured and executive programs concerning promote mental health among the nursing students, which it is important to prepare nursing students to accomplish their experiences more effectively.
\end{abstract}

Key Words: Mental health promotion, Nursing students, Sense of coherence, Defense mechanisms style

\section{INTRODUCTION}

Mental health is an integral and essential component of health. World Health Organization stated that the creation of living conditions and environments that support mental health and allow people to adopt and maintain healthy lifestyles. ${ }^{[1]}$ Additionally, The Ottawa Charter emphasizes the process of empowering people and communities to increase control over the determinants of their health as a critical component in mental health promotion. ${ }^{[2]}$ It is important to understand the relationship between health promotion and mental health with regard to the need for autonomy of the individual in psychological suffering, providing chances that authorize them to make choices, sharing in the production of their care ${ }^{[3]}$ Keleher \& Armstrong stated that mental health promotion contributes to general health promotion by taking action to make sure social conditions and factors make positive environments for good mental health and wellbeing of individuals, especially nurses. In 2005, the world health organization established that the promotion of mental health as a public health main concern, and recognized the importance of intervening primarily in young people. ${ }^{[4]}$

The mental health of young people is a critical issue, as it has an effect not only on the health of this age group but also for them in the future adult years. The mental health problems might interfere the way the young people think, feel, and act.

*Correspondence: Mona M. Abd El-Maksoud; Email: Drmona158@gmail.com; Address: Nursing College, King Khalid University, Saudi Arabia. 
These problems limit their ability to be productive, hinder their academic achievement, and cause family conflicts. Additionally, it can be very costly to families, the community and also to the health and social systems as a whole. ${ }^{[5]}$

Evidence ascertains the efficiency of a wide range of mental health promotion programs. The results demonstrate that mental health promotion is a practical option within a public health approach across the lifespan and different settings as primary care settings, schools, work and local communities. In numerous fields of life, well-designed interventions can contribute to better mental health and well-being of the population. ${ }^{[6]}$ The previous research studies concern that defense mechanisms styles and sense of coherence (SOC) were conducted as a conceptual framework to study mental health.

Sense of coherence is a theoretical construct defined as the belief that what happens in life is comprehensible (the ability to perceive stimuli as ordered, consistent, clear and structured, predictable and explicable), manageable (the ability to perceive that inner and/or outer resources are available, under control and adequate to meet the environmental demands) and meaningful (the extent to which the individual finds demands as important, challenging, committed and worthy of investment and engagement). ${ }^{[7]}$ The results of prior study founded that the sense of coherence was positively correlated with mature defense, however negatively correlated with neurotic and immature defense. ${ }^{[8]}$ Defense mechanisms are mental activities used at the unconscious level to protect the ego against anxiety and conflict situation, also protect the individuals' self-esteem and sense of security. ${ }^{[9]}$

The last decades have witnessed the development of effective programs to promote mental health; nursing school setting is considered the privileged context to develop such initiatives. ${ }^{[1]}$ Regarding to the increasing changes of society and development of social communications, preparation of individuals, especially the nursing students, for facing difficult situations is an essential issue. Preparing to become a nurse involves meeting contradicting demands, feeling more worked, feeling untrained and in searching of respect and support from others, it causes stress and a possible risk to the welfare of students. ${ }^{[10]}$ In addition, uniqueness of nursing profession is significantly and straight related to individual health. Therefore, nursing students should be alert and able to use the nursing theoretical aspects for high quality clinical practicing. ${ }^{[11]}$ So if nursing students are unable to deal with stress in everyday life, they will expand health problems. This study will develop several activities in intervention were created for promote mental health and prepare efficient nursing professionals for the future.

\subsection{The aim of this study}

This study was designed to evaluate the effective of training program on promoting mental health of nursing students through the following objectives:

(1) Assess the a sense of coherence, and self defense mechanism among nursing students

(2) Developed and implemented training program for nursing students to promote a sense of coherence, and improve the self defense mechanism.

\subsection{Hypothesis}

The training program has positive effect on promoting mental health of nursing students.

\section{SUBJECTS AND METHODS}

\subsection{Research design}

A quasi-experimental design was used in this study.

\subsection{Sample and setting}

A convenience sample was selected from students in 4th year studied the community health nursing course during 2015/2016 academic year at the Faculty of Nursing, Zagazig University. $130(89.7 \%)$ of the students were accepted to participate in this study. The volunteer groups was randomly assigned as 65 intervention, and 65 control groups.

\subsection{Tools of data collection}

It consists of three-section questionnaire.

A) The personal characteristics included age, sex, marital status, residence, family income, parents' education and their relations with themself and student.

B) Sense of Coherence Questionnaire: The SOC-29 questionnaire consists of 29 items (16 positive and 13 negative items) with 5 point semantic differential scale for evaluating sense of coherence level. Higher total score reflected the stronger sense of coherence. ${ }^{[12]}$ Cronbach's alpha coefficient for the questionnaire items was 0.86 (from the previous study). ${ }^{[8]}$

C) Thai Defense Style Questionnaire: The Thai Defense Style Questionnaire (DSQ) scale was used to measure the characteristics of defense style and contains 40 items that evaluate defense style through 3 subscales. The mature style (8 items) subscale consists of four defenses (sublimation, humor, anticipation and suppression). The neurotic style (8 items) subscale consists of four defenses (undoing, pseudoaltruism, idealization and reaction formation) as well. The immature style (24 items) consists of twelve defenses (projection, passive aggression, acting-out, isolation, devaluation, autistic fantasy, denial, displacement, dissociation, splitting, rationalization and somatization). The items of these three 
sub-scales were rated on 5 point Likert scale ranging from 1 (strongly disagree) to 5 (strongly agree). High score in each item reflects the frequency with which each defense mechanism is preferred by the respondent. The reliability correlation for DSQ-40 had been reported as $r=0.88$. $^{[13]}$

\subsection{Ethical clearance}

The aim of the study was explained to subjects prior to seeking their participation in the study. They were given an opportunity to refuse to participate in the study. They were notified that they could withdraw at any stage of the research study and that don't affect their grades. Finally, they were assured that their information would be confidential and will be used for the research purpose only.

\subsection{Pilot study}

A pilot study was conducted on $10 \%$ sample students from other fourth group to evaluate the content of the tools, as well as to assess the time need, and clarity of the tools, the necessary modifications were done, namely rephrasing, utilizing simpler semantic for the statements.

\subsection{Data collection procedure Stage 1: Preparatory phase}

A review of the current, past, local and international related literature review was done for preparation the intervention program and data collecting tools.

Moreover, an official written permission was obtained to conduct the study from the Dean, Faculty of Nursing, Zagazig University and from the head of community health nursing department.

\section{Stage 2: Recruitment and group allocation}

Fourth year undergraduate nursing students were contacted through in class announcements. Potential participants were asked to provide verbal consent if they agree to participate. Students who agree to participate were randomly assigned to the study or control group. The researchers contacted the students to explain the purpose and procedure of the study. This study occurred through twice per week.

\section{Stage 3: Pre test assessment}

Participants from the study groups were asked to complete a baseline questionnaire, which was one week prior to the intervention.

\section{Stage 4: The intervention program}

Based on the review of relevant literature, an education program was developed. Sessions were given to the intervention group of students in sixteen sessions of 1 hour each. Each education session was 1 hour, two sessions per week and the implementation of the education program was covered in two-month duration. During program implementation, the researchers complied the health education program booklets and handouts on the program sessions.

Program objectives:

(1) To understand the meaning and importance of positive thinking and how to develop.

(2) To define team building, determine characteristics of effective team.

(3) To recognize roles in building team, and roles that break team.

(4) To determine stages of team building.

(5) To understand and develop the self.

(6) To identify who need help and how to help.

(7) To manage anger and overcome stressors.

(8) To improve the level of communication skills

- First and second sessions: Introduction and providing information about the content of the program, time of sessions, and completing the questionnaire.

- Third session: Positive thinking and its benefits, and ways to develop it.

- Fourth session: Practice exercises to develop positive thinking including replacement exercise, visualization, and journaling.

- Fifth session: Concept of team building including definition and characteristics of effective team.

- Sixth session: Roles in team building and perception of roles that destroy team.

- Seventh session: Role of team leader and stages of team building.

- Eighth session: Team building exercises included the "you", take me high, queen for a day, rings a bell, and my dream trip.

- Ninth session: Self-awareness and understanding human development.

- Tenth session: The Johari window

- Eleventh sessions: Self-awareness focusing on who I am, building self-identity and inside and outside masks exercises.

- Twelfth sessions: Caring and concern (who need help and how to help).

- Thirteenth sessions: Anger \& stress management.

- Fourteenth sessions: Overcoming stressors.

- Fifteenth sessions: Effective communication skills.

- Sixteenth sessions: Last session of health edu- 
cation program that focused on identifying students' opinion about the sessions' benefit.

Each education session was 1 hour, two sessions per week and the implementation of the education program was covered in two-month duration. During program implementation, the researchers were complied with the distribution of the health education program booklets and hand-outs on the program sessions, the duration of study was three months, started from beginning of December 2015 to the end of February 2016.

\section{Stage 5: Post-intervention}

Immediately after training completion, the post assessment data collection was performed with both groups using the same questionnaire to evaluate the effect of intervention. Data collection lasted for three months.

\subsection{Data analysis}

Descriptive statistics tests including the mean, standard deviation, frequency, percentages were computed. The Chisquare test was used to measure the differences of socio demographic characteristics between intervention and control group. Paired $t$-tests were used to compare scores of the defense mechanisms styles and sense of coherence between intervention and control groups. Paired $t$-tests were also employed to analyze differences within groups in pre and post program. Logistic regression was used to assess changes in dichotomous variables. The significance level was .05. Data were analyzed using the SPSS version 17.

\section{Results}

According to Table 1, majority of students in intervention and control group were female $(73.8 \% \& 78.5 \%$ respectively), and live in rural areas $(86.2 \% \& 78.5 \%$ respectively). The mean age of students in intervention and control group was ( $21.83 \pm .67$ and $22.00 \pm 0.63$ respectively). $73.4 \%$ of students' mother in intervention group had no occupation, and 46.9\% have secondary education. Mothers of the control group revealed that many of them did not have occupation and secondary education $(66.1 \%, 38.7 \%$ respectively). More than one third of students' father in intervention and control group had secondary education $(39.3 \% \& 35.6 \%)$.

Table 1. Percentage distribution of personal characteristics of the studied groups

\begin{tabular}{|c|c|c|c|c|c|c|c|}
\hline \multirow{2}{*}{\multicolumn{2}{|c|}{ Personal characteristics }} & \multicolumn{2}{|c|}{ Study group $(n=65)$} & \multicolumn{2}{|c|}{ Control group $(n=65)$} & \multirow{3}{*}{$\begin{array}{l}\chi^{2} \\
t \text {-test: } 1.47\end{array}$} & \multirow{3}{*}{$\begin{array}{l}\boldsymbol{p} \text {-value } \\
.14\end{array}$} \\
\hline & & No & $\%$ & No & $\%$ & & \\
\hline Students' age & Mean \pm SD & \multicolumn{2}{|c|}{$21.83 \pm 0.67$} & \multicolumn{2}{|c|}{$22.00 \pm 0.63$} & & \\
\hline \multirow{2}{*}{ Students' gender } & Female & 48 & 73.8 & 51 & 78.5 & \multirow{2}{*}{0.52} & \multirow{2}{*}{.47} \\
\hline & Male & 17 & 26.2 & 14 & 21.5 & & \\
\hline \multirow{2}{*}{ Residence } & Rural & 56 & 86.2 & 51 & 78.5 & \multirow{2}{*}{1.66} & \multirow{2}{*}{.20} \\
\hline & Urban & 9 & 13.8 & 14 & 21.5 & & \\
\hline \multirow{2}{*}{ Mothers' occupation } & Unemployed & 47 & 73.4 & 41 & 66.1 & \multirow{2}{*}{0.80} & \multirow{2}{*}{.37} \\
\hline & Employed & 17 & 26.6 & 21 & 33.9 & & \\
\hline \multirow{5}{*}{$\begin{array}{l}\text { Mothers' educational } \\
\text { level }\end{array}$} & Illiterate & 18 & 28.1 & 14 & 22.6 & \multirow{5}{*}{3.03} & \multirow{5}{*}{.55} \\
\hline & Read and write & 6 & 9.4 & 11 & 17.7 & & \\
\hline & Primary education & 2 & 3.1 & 3 & 4.8 & & \\
\hline & Secondary education & 30 & 46.9 & 24 & 38.7 & & \\
\hline & Higher education & 8 & 12.5 & 10 & 16.1 & & \\
\hline \multirow{5}{*}{$\begin{array}{l}\text { Fathers' educational } \\
\text { level }\end{array}$} & Illiterate & 5 & 8.9 & 6 & 10.2 & \multirow{5}{*}{2.75} & \multirow{5}{*}{.60} \\
\hline & Read and write & 5 & 8.9 & 8 & 13.6 & & \\
\hline & Primary education & 6 & 10.7 & 3 & 5.1 & & \\
\hline & Secondary education & 22 & 39.3 & 21 & 35.6 & & \\
\hline & Higher education & 18 & 32.1 & 21 & 35.6 & & \\
\hline \multirow{3}{*}{ Family income } & Sufficient and save & 28 & 43.1 & 18 & 27.7 & \multirow{3}{*}{4.99} & \multirow{3}{*}{.08} \\
\hline & Sufficient only & 33 & 50.8 & 40 & 61.5 & & \\
\hline & Insufficient & 4 & 6.2 & 7 & 10.8 & & \\
\hline \multirow{3}{*}{$\begin{array}{l}\text { Student relation with } \\
\text { parents }\end{array}$} & Usual & 52 & 80.0 & 49 & 75.4 & \multirow{3}{*}{1.31} & \multirow{3}{*}{.52} \\
\hline & Spoiled & 13 & 20.0 & 15 & 23.1 & & \\
\hline & Aggressive & 0 & 0.0 & 1 & 1.5 & & \\
\hline \multirow{3}{*}{ Parents relation } & Usually aggressive & 2 & 3.1 & 3 & 4.6 & \multirow{3}{*}{1.56} & \multirow{3}{*}{.46} \\
\hline & Sometimes aggressive & 35 & 53.8 & 28 & 43.1 & & \\
\hline & Good relation & 28 & 43.1 & 34 & 52.3 & & \\
\hline
\end{tabular}


More than half of students in study and control group have sufficient income (50.8 \& $61.5 \%$ respectively). Majority of students in intervention and control group have usual relation with their parents $(80.0 \%, 75.4 \%$, respectively). More than half of students' parents in intervention group sometimes had aggressive relationship (53.8\%). However, in control group, parents' relation was good (52.3\%). No statistical significant difference between intervention and control groups were found in all socio-demographic characteristics except fathers' age $(p=.02)$.

As shown in Table 2, there was a statistically significant dif- ference in mean scores present between pre and post program in intervention group in all variables $(p<.01)$ except total defense style $(p=.603)$. However, in the control group no significant difference in mean scores was present between pre and post program on any variable except comprehensibility ( $p=.007)$, and total of SOC ( $p=.034)$. Additionally, no statistically significant difference was founded between intervention and control group at pre-program in all study' variables. However, a highly statistically significant difference in mean scores was present intervention study and control group at post program $(p<.01)$ in all study's variables except total defense style $(p=.06)$.

Table 2. Comparing the mean scores of sense of coherence and defense style in the study and control group at pre and post program

\begin{tabular}{|c|c|c|c|c|c|}
\hline Variables & & Study & Control & $T$ test & $p$-value \\
\hline \multicolumn{6}{|l|}{ Sense of coherence } \\
\hline \multirow{4}{*}{ Manageability } & Pre & $31.31 \pm 5.89$ & $30.97 \pm 4.53$ & & \\
\hline & Post & $39.0 \pm 7.08$ & $31.85 \pm 4.40$ & 0.367 & .714 \\
\hline & Paired $t$ test & 7.814 & 1.273 & 6.921 & $.000 * *$ \\
\hline & $p$-value & $.000 * *$ & .208 & & \\
\hline \multirow{4}{*}{ Comprehensibility } & Pre & $29.83 \pm 6.39$ & $28.58 \pm 5.34$ & & \\
\hline & Post & $37.86 \pm 7.06$ & $31.02 \pm 6.17$ & 1.207 & .230 \\
\hline & Paired $t$ test & 8.017 & 2.772 & 5.889 & $.000 * *$ \\
\hline & $p$-value & $.000 * *$ & $.007 * *$ & & \\
\hline \multirow{4}{*}{ Meaning } & Pre & $24.43 \pm 3.56$ & $24.51 \pm 3.69$ & & \\
\hline & Post & $28.65 \pm 3.67$ & $24.88 \pm 3.55$ & 0.121 & .904 \\
\hline & Paired $t$ test & 8.882 & 0.542 & 5.953 & $.000 * *$ \\
\hline & $p$-value & $.000 * *$ & .590 & & \\
\hline \multirow{4}{*}{ Total sense of coherence } & Pre & $85.57 \pm 13.32$ & $84.06 \pm 10.45$ & & \\
\hline & Post & $105.51 \pm 16.39$ & $87.74 \pm 10.83$ & 0.718 & .474 \\
\hline & Paired $t$ test & 8.709 & 2.169 & 7.291 & $.000 * *$ \\
\hline & $p$-value & $.000 * *$ & $.034^{*}$ & & \\
\hline \multicolumn{6}{|l|}{ Defense style } \\
\hline \multirow{4}{*}{ Neurotic } & Pre & $26.92 \pm 4.30$ & $27.92 \pm 4.14$ & & \\
\hline & Post & $30.65 \pm 3.35$ & $27.54 \pm 3.82$ & 1.350 & .179 \\
\hline & Paired $t$ test & 8.127 & 0.577 & 4.933 & $.000 * *$ \\
\hline & $p$-value & $.000 * *$ & .566 & & \\
\hline \multirow{4}{*}{ Mature } & Pre & $27.74 \pm 4.25$ & $28.54 \pm 3.13$ & & \\
\hline & Post & $29.89 \pm 2.61$ & $28.0 \pm 3.73$ & 1.221 & .224 \\
\hline & Paired $t$ test & 4.266 & 1.004 & 3.351 & $.001 * *$ \\
\hline & $p$-value & $.000 * *$ & .319 & & \\
\hline \multirow{4}{*}{ Immature } & Pre & $71.42 \pm 13.39$ & $74.71 \pm 10.79$ & & \\
\hline & Post & $64.23 \pm 11.12$ & $74.11 \pm 11.65$ & 1.543 & .125 \\
\hline & Paired $t$ test & 3.688 & 0.370 & 4.944 & $.000 * *$ \\
\hline & $p$-value & $.000 * *$ & .713 & & \\
\hline \multirow{4}{*}{ Total defense style } & Pre & $126.08 \pm 18.56$ & $131.17 \pm 15.63$ & & \\
\hline & Post & $124.85 \pm 11.59$ & $129.65 \pm 16.65$ & 1.692 & .093 \\
\hline & Paired $t$ test & 0.523 & 0.618 & 1.884 & .06 \\
\hline & $p$-value & .603 & .538 & & \\
\hline
\end{tabular}

${ }^{*} p<.05, * * p<.01$ 
Figure 1 illustrated that the mean score of total sense of coherence of intervention group increased from pre 85.57 to 105.51 at post, also the control group had some improved. In relation to total defense style, the mean score of intervention group changed from pre 126.08 to 124.85 post. Moreover, the mean score of control group was 131.17 at pre, but decrease at post to 129.65 .

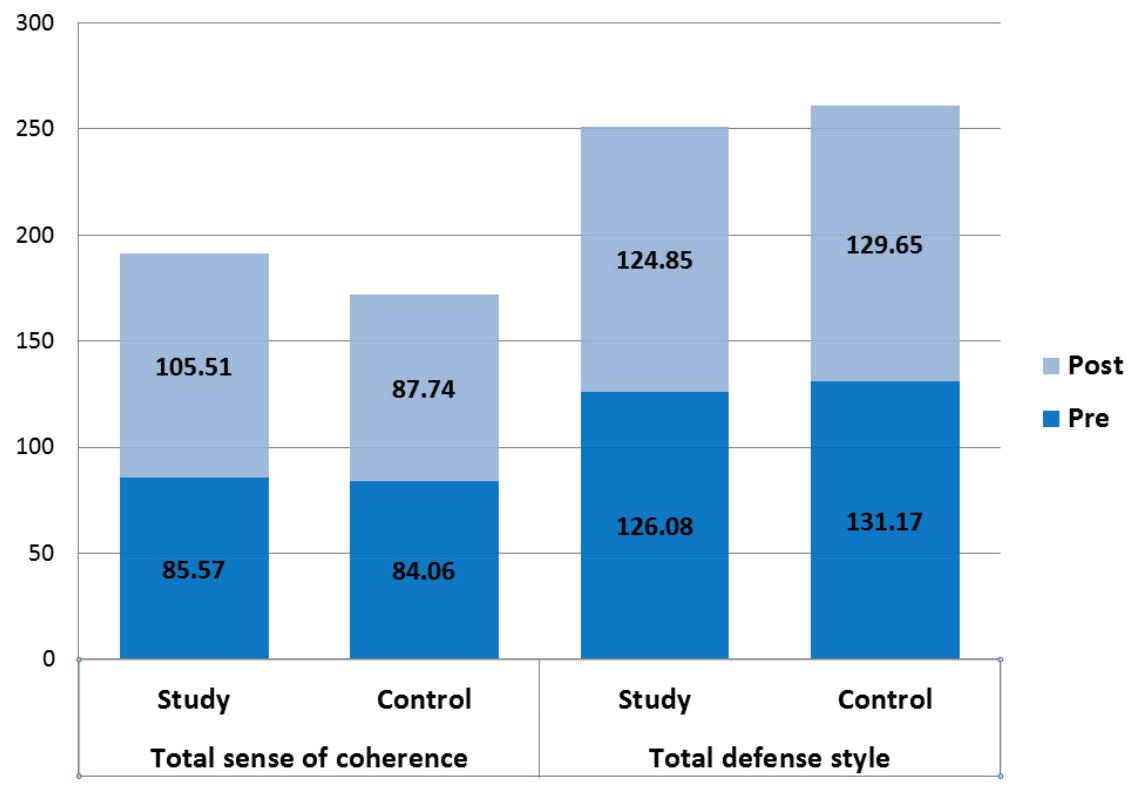

Figure 1. Total mean score of study and control group at pre and post program

Table 3 presented the multivariate analysis which revealed that the gender and the intervention program were highly significant predictors for good sense of coherence. But the findings didn't show any significant on defense style.

Table 3. Logistic regression analysis of factor predicting good sense of coherence

\begin{tabular}{lllll}
\hline Variables & B & SE & Wald & p value \\
\hline Intervention versus control & 2.267 & 0.473 & 22.996 & .000 \\
Student gender (male versus female) & 2.516 & 0.616 & 16.684 & .000 \\
\hline
\end{tabular}

\section{Discussion}

This pilot study aimed to promote mental health of nursing students. Promoting mental health in the setting where nursing students socialize, live and study is important and will likely influence their attitudes towards mental health and wellbeing and increase the proficiency of nursing students in the future.

Prior to implementing the training program to promote mental health of nursing students, there was no statistically significant between the intervention group and control on sociodemographic characteristics and the mean score near to each other in sense of coherence and defense style which supports the conclusion that both groups were equal.

Results supported that the intervention program increased participants' sense of coherence. These young participants scores were higher than those obtained by young participant in Valencia $54.4 ;^{[14,15]}$ and those attained by Spanish nursing professionals: $67.4{ }^{[16]}$ but lower than those obtained by a study carried out among students published in Poland, different results for SOC values were 125.2..$^{[17]}$ Also the result indicating that the sense of coherence structure there was increase in consequence from manageability (31.31), comprehensibility (29.83), and then meaningfulness (24.43). The findings of this research were consistent with findings reported by Deeromarm, et al. ${ }^{[8]}$

Consistent with other studies, this study results showed that statistically significant improvement in mean scores between pre and post program in intervention group in all sense of coherence dimensions which supports the effectiveness of mental health promoting program. According to Eriksson $\&$ Lindstrom, the sense of coherence is positively correlated with health status, especially mental health. Thus, mental 
health may be enhanced through promoting sense of coherence. ${ }^{[18]}$ Similarly Langeland et al. reported that SOC improved significantly from pre to post program. ${ }^{[19]}$ Moreover, the control group had significant difference on comprehensibility as evidenced by the total score of sense of coherence from pre to post program. This is consistent with the findings of the previous study. ${ }^{[8]}$

The study findings showed that there was no statistically significant difference between the adequate senses of coherence and socio-demographic of studied group except for gender, and the gender was the predictor factor for good sense of coherence (see Table 3). This may be related to the way of education and difference in gender roles and associated social requirements. There were significant differences in physically, moral, and their roles of family between male and female. According to SOC theory, the gender differences may reflect that girls see life as less coherent than boys; hence, they are more susceptible to a negative health development. These results are in consistency with Moksnes, et al showed that a significant main effect of gender on SOC, where boys had higher mean scores than girls $(p<.001){ }^{[20]}$ On other hand, a study done in India by Suraj $\&$ Singh found that significant association between SOC scores and age of students and family income. ${ }^{[7]}$

Regarding the defense mechanism the findings of the both the intervention and control groups showed that no statistically significant difference of all items of defense mechanisms pre-intervention phase. Results also indicated that the mean score of defense style dimension consequence was neoteric defense style 26.92, mature defense style 27.72 and immature defense style was 71.42. On the other hand, the results of a study done by Irandoust, et al. who found that the highest mean score of all levels of defense mechanism. ${ }^{[21]}$ Our results also show that the both group has high score for immature level of defense mechanism. This consistence with the results of previous studies which find that the high score immature level of defense mechanism. ${ }^{[8,22]}$

After implementing the program, the findings illustrated that there statistically significant difference between pre to post program for intervention group through using neurotic defense mechanisms, which the intervention group indicated higher scores than the control group with statistically significant difference. Thus, training program improved using students' neurotic defensive mechanisms. ${ }^{[23]}$ On the same line, Moshtaqi, et al. showed that the scores of neurotic defensive mechanisms are improved after training.

Concerning the mature score, the results illustrated that the mean score of mature style increase from pre to post among intervention group with significant different also with control group at post program. This might be explained that the training program improved using students' mature mechanisms. These findings are in agreement with previous research about the impact of training on mature defensive mechanisms. ${ }^{[24,25]}$ This is not aligned with results of study done by Moshtaqi, et al. who considered that the main effect of training variable on the scores of mature defensive mechanisms of post-test is not significant. ${ }^{[23]}$

Regarding the immature score, the findings indicated that the intervention group had lower mean score than control group and changed from pre to post with significant different between them. Thus, training program improved using students' immature defensive mechanisms. The finding of this research is aligned with the finding of the research by Khodabakhsh. ${ }^{[26]}$ Inconsistency with Moshtaqi, et al. they implemented an intervention study on defense mechanism and found that the intervention group had more scores in terms of immature defense style than control group students, and stated that the main effect of training variable on the scores of immature defensive mechanisms of post-test is not significant $(p=.12) .{ }^{[23]}$

Consistent with other studies, the current study results show that the mean score of the defense mechanisms decrease from pre to post training program and decrease than those of control group with near to significant $(p=.06)$. In explaining these findings, it can be stated that defense style is vital factors to students' mental health. Therefore, mental health education should help nursing students understand their own defense styles and establish a mature defense style to deal with all kinds of stress to maintain their self-consistency. These results are inconsistent with Noorbala, et al. which concluded that, based on this training, defensive mechanisms significantly decreased in the experimental group compared to the control group $(p<.05) .^{[25]}$

According to research hypothesis regarding the positive effect of training program on promoting mental health of nursing students, it had clearly achieved, the results were established by improved necrotic, mature defense mechanisms and decreased immature and improved the level of sense of coherence, these indicated the efficiency of this intervention. Mental health promotion, as public education, can increase the level of knowledge and have a positive effect on the various dimensions of human life. Which the students are the future leaders of the society; their mental health is of great importance. Similarly, this research is aligned with that of previous researches that showed education skills including, time management, positive thinking, team work, communication skills and the skill of self-expression can promote individuals' mental health. ${ }^{[27]}$ 


\section{CONCLUSION AND RECOMMENDATION}

This study showed that training intervention is effective in promote mental health of nursing students through improvement of sense of coherence manageability, comprehensibility, and meaning, also improvement in defense style that include neurotic, mature, and immature, was detected as a result of training intervention program which had several activities focusing on the manipulation of both internal and external factors that affects mental health of nursing students. Therefore, it is essential to conduct further structured and executive programs concerning promote mental health among the students, which it is important to prepare nursing students to accomplish their experiences more effectively.

\section{CONFlicts OF InTEREST Disclosure}

The authors declare that there is no conflict of interest.

\section{REFERENCES}

[1] World Health Organization. Mental Health Promotion in Young People-an investment for the future. 2010. [Online] Available from: http://www.euro.who.int/__data/assets/pdf_fil e/0013/121135/E94270

[2] Barry MM, Allegrante JP, Lamarre MC, et al. The Galway Consensus Conference: International collaboration on the development of core competencies for health promotion and health education. Global Health Promot. 2009; 16(2): 5-11. PMid:19477858 https ://doi.org/10.1177/1757975909104097

[3] Aguiar MI, Lima HP, Braga VA, et al. Nurse competencies for health promotion in the mental health context. Acta paul. enferm. 2012; 25 (spe2) São Paulo. https : //doi .org/10.1590/S0103-2100201 2000900025

[4] Keleher H, Armstrong R. Evidence-based mental health promotion resource, Report for the Department of Human Services and Vic Health, Melbourne; 2005.

[5] Campos L, Dias P, Palha F. Finding Space to Mental Health1 - Promoting mental health in adolescents: Pilot study. Education and Health. 2014; 32(1): 23-29.

[6] Sturgeon S. Health promotion challenges: Promoting mental health as an essential aspect of health promotion. Health Promotion International. 2007; 21 (S1): 36-41.

[7] Suraj S, Singh A. Study of sense of coherence health promoting behavior in north Indian students. Indian J Med Res. 2011; 134: 645-652. PMid:22199103 https://doi.org/10.4103/0971-5 916.90989

[8] Deeromram C, Suwannimitr S, Jundeekrayom S. Mental Health Promotion among Nursing Students. Journal of Social Sciences. 2010; 6(2): 133-140. https://doi.org/10.3844/jssp. 2010. 133.140

[9] Shives LR, Isaacs A. Basic Concept of Psychiatric-Mental Health Nursing. (6th Ed.); 2005.

[10] Berman A, Kozier SS. Fundammental of nursing concept process and practice (9th ed.). New Jersey: Pearson Prentice Hall; 2012.

[11] Lambert VA, Lambert CE, Petrini M, et al. Workplace personal factors associated with physical and mental health in hospital nurses in China. Nurs. Health Sci. 2007; 9: 120-126.

[12] Bengtsson-Tops A, Hansson L. The validity of Antonovsky's sense of coherence measure in a sample of schizophrenic patients living in community. J. Adv. Nurs. 2001; 33: 432-438. PMid:11251730 https://doi.org/10.1046/j.1365-2648.2001.01692.x

[13] Kipper L, Blaya C, Wachleski C, et al. Trauma and defense style as response predictors of pharmacological treatment in panic patients. Eur. Psychiatry. 2007; 22: 87-91. PMid:17188844 https: //doi.org/10.1016/j.eurpsy.2006.09.009
[14] Lindström B, Eriksson M. Salutogenesis. Journal of Epidemiology and Community Health. 2005; 59: 440-442. PMid:15911636 https://doi.org/10.1136/jech.2005.034777

[15] Paredes-Carbonell JJ, Agullo-Cantos JM, Vera-Remartinez EJ, et al Sense of coherence and health assetsin a youth center for minors. Rev EspSanidPenit. 2013; 15: 87-97.

[16] Malagon MC, Juvinya D, Bonmati A, et al. Sentido de Coherencia de lasenfermeras y validacion del cuestionario SOC-13. Metas de Enferm. 2012; 15(9): 27-31.

[17] Binkowska-Bury M, Kruk W, Szymanska J, et al. Psychosocial factors and health-related behavior among students from SouthEast Poland. Ann Agric Environ Med. 2010; 17(1): 107-13. PMid:20684487

[18] Eriksson M, Lindstrom B. Antonovsky's sense of coherence scale and the relation with health: a systematic review. J Epidemiol Community Health. 2006; 60(5): 376-81. PMid:16614325 https : //doi.org/10.1136/jech.2005.041616

[19] Langeland E, Robinson HS, Moum T, et al. Promoting sense of coherence: Salutogenesis among people with psoriasis undergoing patient education in climate therapy. BMC Psychology. 2013; 1(11): 1-8. https ://doi.org/10.1186/2050-7283-1-11

[20] Moksnes UK, Espnes GA, Lillefjell M. Sense of coherence and emotional health in adolescents. Journal of Adolescence. 2011. 1-9 p https://doi.org/10.1016/j.adolescence.2011.07.013

[21] Irandoust R, Mozafari E, Ghaderi J, et al. Studying the Relationship between Defense Styles, Self-esteem, and Depression Symptoms among Female Students (High Schools of Baft City as Case Study). Switzerland Research Park Journal. 2014; 104 (1): 64-70.

[22] Shichiri K, Shibuya M, Murayama K, et al. Features of Developmental Level of Defense Mechanisms and Adjustment Status of University Students in Japan. Health. 2015; 7: 52-57. http: //dx.doi.org/10.4236/health.2015.71007

[23] Moshtaqi F, Daramadi PS, Esmaeili A. Analysis of the Effect of Training Life Skills on Defensive Mechanismsand Styles of Students' Attachments. European Online Journal of Natural and Social Sciences. 2014; 3(3): 671-677.

[24] Basharat MA. Alexithymia and defensive style. Journal of primary and mental health. 2008; 3(39): 181-190.

[25] Noorbala AA, Pour A, Shaghaghi F, et al. The effect of training written emotional disclosure on depression severity and use of defensive mechanisms in depressed patients. Bimonthly Scientific - Research, Shahed University. 2011; 18-93.

[26] Khodabaksh MR. The relationship between attachment styles and empathy in nursing students, Journal of Nursing Research Center, Tehran University of Medical Sciences (Iranian Nursing Journal 2012; 25 (77): 49-40.

[27] Sahebalzamani M. Efficacy of neurolinguistic programming training on mental health in nursing and midwifery students. Iran J Nurs Midwifery Res. 2014; 19(5): 503-507. PMid:25400679 